\title{
Structurally tailored carbon xerogels produced through a sol-gel process in a water-methanol-inorganic salt solution
}

\author{
Wojciech Kiciński • Mateusz Szala • \\ Marcin Nita
}

Received: 5 October 2010/Accepted: 8 November 2010/Published online: 18 November 2010

(C) The Author(s) 2010. This article is published with open access at Springerlink.com

\begin{abstract}
The impact of solvent composition as well as inorganic salt content and type on carbon xerogel structure was investigated. Carbon xerogels were derived from the sol-gel polycondensation of resorcinol with furfural in a water-methanol-inorganic salt solution. As inorganic salts, $\mathrm{NaCl}, \mathrm{NH}_{4} \mathrm{ClO}_{4}$ and $\mathrm{FeCl}_{3}$ were used. In order to conduct an accurate examination of the carbon xerogel structures and textures, inorganic salts were removed prior to carbonization. The xerogel structures can be tailored according to the water/methanol ratio and, to a lesser extent, according to the inorganic salt content and type in the starting solution. As a result, a significant amount of salt can be introduced to the gel network of the desired structure. The morphology and physical properties of the organic xerogels, carbon xerogels and their composites were characterized by means of SEM, $\mathrm{N}_{2}$ sorption and $\mathrm{XRD}$. It was found that samples derived from mixtures with $\mathrm{FeCl}_{3}$ manifest well developed mesoporosity and depleated microporosity in comparison to samples prepared from mixtures with $\mathrm{NaCl}$ and $\mathrm{NH}_{4} \mathrm{ClO}_{4}$. Iron ions chemically bond to the xerogel matrix and cause its partial graphitization during the carbonization process, resulting in enhanced mesoporosity.
\end{abstract}

Keywords Carbon xerogel - Organic xerogel . Sol-gel process · Carbonization · Microcellular carbon . Phase separation

W. Kiciński (凹) · M. Szala · M. Nita

Military University of Technology, Kaliskiego 2,

00-908 Warsaw, Poland

e-mail: wkicinski@wat.edu.pl

\section{Introduction}

Owing to their high porosity, open pore network, easily tailored and replicable continuous structure, high surface area and attractive electrochemical properties, carbon gels (aero-, xero-, and cryo-gels) are drawing a lot of attention lately [1-29]. Their interesting properties can be additionally modified and enhanced through activation, graphitization, composition with conductive nanostructures (i.e. carbon nanotubes, carbon nanofibers) and doping with inorganic materials (metal, metal oxides, carbides, or phosphides) [3-17, 23]. The modified carbon gels have a range of potential applications, in particular, in adsorption, catalysis, fuel cells, supercapacitors and batteries [18-31].

Complicated and time-consuming supercritical extraction and freeze-drying make aero- and cryogels less attractive for economical reasons, thus favoring carbon xerogels (CXs), which are obtained through simple evaporative drying and carbonization of organic gels [32]. From a short literature review one can conclude that many methods to prepare xerogels with enhanced porosity have been proposed [33-44]. Job and co-workers showed in detailed research that for the set resorcinol/formaldehyde molar ratio and dilution, monolithic, porous xerogels with tailored structure and high values of pore volume and specific surface area $\left(\sim 2 \mathrm{~cm}^{3} / \mathrm{g}\right.$ and $\sim 700 \mathrm{~m}^{2} / \mathrm{g}$, respectively) can be obtained by choosing an appropriate $\mathrm{pH}$ of the precursor solution [18, 40-43]. This procedure can even be shortened if microwaves are employed to dry organic gels [44]. Moreover, they pointed out that for a given $\mathrm{pH}$, the "catalyst' (substance used to adjust $\mathrm{pH}$ ) chemical formula itself, i.e. the particular cations from the 'catalyst' and their concentration, can affect the gel structure [45, 46]. Additionally, research pursuing the doping of resorcinolformaldehyde gels through salt solubilization revealed that 
the presence of inorganic salt in the solution of gel precursors significantly affects the gel structure $[5-8,11,17$, 47-49]. This finding was attributed not only to the $\mathrm{pH}$ modification (salts usually possess acido-basic properties) but also to the cation nature. The solubilization of inorganic salts in the solution of precursors, followed by evaporative drying, yields salt-doped organic xerogels. High homogeneity of those hybrid organic polymer/inorganic salt composites creates an opportunity to obtain new functional materials. For example, organic xerogels doped with perchlorates or nitrates can serve as explosives [50-52], while carbonization of an organic xerogel/metal salt composite leads to metal doped carbon xerogels $[6,8,47,53]$, and in the case of transitions metals, porous graphitic carbon can be obtained after metal removal [15, 27, 30, 54, 55]. Metaldoped carbon xerogels and highly graphitic porous carbons have been widely investigated as candidates for carbon supported metal catalysts [14, 27, 30, 54-57]. All of that suggests that doping of organic gels with inorganic salts via salt solubilization can be an easy and safe way to obtain many interesting functional nanostructured materials.

Since evaporative drying is economically reasonable and doping by salt solubilization is convenient whilst enabling control of the gel structure, it is justified to continue research in this direction. This paper proves that the resorcinol-furfural (R-F) xerogel structure is controllable when the sol-gel process is carried out in water-methanol mixture and the salt is added by solubilization into the precursor solution. It was shown that for a fixed water/methanol ratio, a significant amount of salt can be incorporated into the resorcinol-furfural (R-F) gel network of the desired structure. Since the aim of this research was to precisely analyze the structure of carbon xerogels depending on the starting solution composition (water/methanol ratio and salt amount and type), the salts were removed from the organic xerogel structure, which results in a pure resorcinol-furfural xerogel and, after carbonization, in a carbon xerogel. Salts with three different cations $\left(\mathrm{Na}^{+}, \mathrm{NH}_{4}^{+}, \mathrm{Fe}^{3+}\right)$ were chosen in order to check if this observation can be generalized and extended to other resorcinol-aldehyde/inorganic salt systems. The obtained organic and carbon materials were characterized by means of scanning electron microscopy, surface area analysis, and X-ray diffraction.

\section{Experimental}

\subsection{Preparation}

Organic xerogels (OXs) were obtained from condensation of resorcinol with furfural (R-F gel) carried out in a solution of water, methanol $(\mathrm{MeOH})$ and sodium chloride, ammonium perchlorate or anhydrous $\mathrm{Fe}(\mathrm{III})$ chloride. The molar ratio of furfural to resorcinol was held at a constant value of 2.3, while water/methanol ratio and salts contents were varied gradually. The experimental data of the synthesis of organic xerogel materials are shown in Tables 1,2 and 3. Gelation in water/salt solution (without methanol) did not occur; in this case flocky precipitates were obtained. Water acts as a solvent for inorganic salts, while methanol acts as a co-solvent to increase the solubility of organic components, especially furfural which does not mix with water. Additionally methanol is very easy to remove during conventional drying. With the exception of mixtures with $\mathrm{FeCl}_{3}$, which easily hydrolyzes to $\mathrm{HCl}$, solgel polymerization was initiated using concentrated hydrochloric acid [58]. In a typical synthesis, resorcinol, furfural and inorganic salt were dissolved in a water/ methanol mixture. After that, $\mathrm{HCl}(37 \mathrm{wt} \%, 0.8 \%$ of the starting solution in each case) was added to the solutionthe solution's $\mathrm{pH}$ was not monitored. Then the sol mixture was sealed in a beaker and sol-gel polymerization was carried out by holding the mixture at $60{ }^{\circ} \mathrm{C}$. Aqua-alcogel was obtained within a few minutes. The gel was aged for 3 days at $60{ }^{\circ} \mathrm{C}$. Eventually, a bulky, wet organic gel, up to $250 \mathrm{ml}$ in volume and filled with inorganic salt solution was obtained. It is important to be aware of the potentially explosive properties of dry $\mathrm{R}-\mathrm{F} / \mathrm{NH}_{4} \mathrm{ClO}_{4}$ composite and appropriate safety precautions should be taken during operations with that material [52]. The wet monolithic gel was then exposed to a distilled water purification process in order to remove the inorganic salt. The gel samples were boiled three times in excess of water. After being purified, the wet gel was dried under a perforated foil for 3 days at $60{ }^{\circ} \mathrm{C}$, and then without any confinement at $100{ }^{\circ} \mathrm{C}$ for 1 day. As a result, an organic xerogel was obtained. The carbon xerogel was obtained by $\mathrm{OX}$ carbonization at $1,000{ }^{\circ} \mathrm{C}$ for $2 \mathrm{~h}$ with a heating rate of $10^{\circ} \mathrm{C} / \mathrm{min}$, or at $900{ }^{\circ} \mathrm{C}$ for $2 \mathrm{~h}$ with a heating rate of $3{ }^{\circ} \mathrm{C} / \mathrm{min}$, under a flow of pure $\mathrm{N}_{2}$. Some chosen $\mathrm{FeCl}_{3}$-doped xerogels were not washed in water and, after complete drying, the obtained $\mathrm{R}-\mathrm{F} / \mathrm{FeCl}_{3}$ xerogel composite was subjected to carbonization. This process yields a sample containing a reduced form of iron, as revealed by the attraction of that xerogel to a magnet.

Additionally, as a point of reference, some gels were synthesized using a salt-free mixture. Also, for $\mathrm{NaCl}$ and $\mathrm{NH}_{4} \mathrm{ClO}_{4}$-containing samples some syntheses were carried out without adding $\mathrm{HCl}$ in order to check the 'catalytical' properties of those salts. In these cases, in contrast to samples with $\mathrm{FeCl}_{3}$, gelation did not occur and a precipitate was obtained. 
Table 1 Organic xerogel recipes and impact of the precursor sol composition with addition of $\mathrm{NaCl}$ on the drying shrinkage and density of organic xerogel

\begin{tabular}{|c|c|c|c|c|c|}
\hline Test no. & $\begin{array}{l}\text { Examined materials } \\
\text { (starting solution consisting } \\
\text { of R:F:M:W:IS-formula, } \\
\text { amount of substances }[\mathrm{g}] \text { ) }\end{array}$ & $\begin{array}{l}\mathrm{H}_{2} \mathrm{O} / \mathrm{MeOH} \\
\text { mass ratio }\end{array}$ & $\begin{array}{l}\text { Salt content } \\
(\mathrm{wt} \%)\end{array}$ & $\begin{array}{l}\text { Drying shrink } \\
(\%) \pm 5\end{array}$ & $\begin{array}{l}\text { Density }\left(\mathrm{g} / \mathrm{cm}^{3}\right) \\
\pm 0.05\end{array}$ \\
\hline OX-1 & $15: 30: 47.5: 110: 3-\mathrm{NaCl}$ & 2.32 & 1.4 & 44 & 0.36 \\
\hline OX-2 & $15: 30: 47.5: 110: 5-\mathrm{NaCl}$ & 2.32 & 2.4 & 26 & 0.29 \\
\hline OX-3 & $15: 30: 47.5: 110: 9-\mathrm{NaCl}$ & 2.32 & 4.2 & 31 & 0.32 \\
\hline OX-4 & $15: 30: 47.5: 110: 20-\mathrm{NaCl}$ & 2.32 & 8.9 & 28 & 0.28 \\
\hline OX-5 & $15: 30: 31.6: 110: 20-\mathrm{NaCl}$ & 3.48 & 9.7 & - & Precipitate $^{\mathrm{a}}$ \\
\hline OX-6 & $15: 30: 55.3: 110: 9-\mathrm{NaCl}$ & 1.99 & 4.1 & 43 & 0.36 \\
\hline OX-7 & 15:30:71.1:110-salt free & 1.55 & 0 & 85 & $1.23^{\mathrm{b}}$ \\
\hline OX-8 & $15: 30: 71.1: 110: 14-\mathrm{NaCl}$ & 1.55 & 5.8 & 58 & $0.45^{\mathrm{b}}$ \\
\hline OX-9 & $15: 30: 71.1: 110: 20-\mathrm{NaCl}$ & 1.55 & 8.1 & 48 & 0.35 \\
\hline OX-10 & $15: 30: 71.1: 110: 22-\mathrm{NaCl}$ & 1.55 & 8.9 & 45 & 0.33 \\
\hline OX-11 & $15: 30: 71.1: 110: 24-\mathrm{NaCl}$ & 1.55 & 9.6 & 50 & 0.33 \\
\hline OX-12 & 15:30:71.1:110:24-NaCl-HCl free & 1.55 & 9.6 & - & Precipitate $^{\mathrm{a}}$ \\
\hline OX-13 & $15: 30: 71.1: 110: 26-\mathrm{NaCl}$ & 1.55 & 10.3 & 50 & 0.32 \\
\hline OX-14 & $15: 30: 71.1: 110: 30-\mathrm{NaCl}$ & 1.55 & 11.7 & 41 & 0.31 \\
\hline OX-15 & $15: 30: 55.3: 130: 26-\mathrm{NaCl}$ & 2.35 & 10.1 & 26 & 27 \\
\hline OX-16 & $15: 30: 47.5: 140: 26-\mathrm{NaCl}$ & 2.95 & 10.1 & - & Precipitate $^{\mathrm{a}}$ \\
\hline OX-17 & $15: 30: 55.3: 130$-salt free & 2.35 & 0 & 47 & $0.33^{\mathrm{b}}$ \\
\hline OX-18 & $15: 30: 47.5: 140$-salt free & 2.95 & 0 & 36 & 0.28 \\
\hline OX-19 & $15: 30: 39.5: 150$-salt free & 3.80 & 0 & - & Precipitate $^{\mathrm{a}}$ \\
\hline $\mathrm{OX}-20 / \mathrm{NaCl}^{\mathrm{c}}$ & 7.5:15:55.3:80:18-NaCl & 1.45 & 10.2 & 61 & 0.85 composite $\mathrm{R}-\mathrm{F} / \mathrm{NaCl}^{\mathrm{b}}$ \\
\hline OX-21 & 7.5-15-55.3:90:16-NaCl & 1.63 & 8.7 & 52 & 0.27 \\
\hline OX-22 & 7.5-15-55.3:90:18- NaCl & 1.63 & 9.7 & 54 & 0.28 \\
\hline OX-23 & 7.5:15:71.1:110:18-NaCl & 1.55 & 8.1 & 75 & $0.44^{\mathrm{b}}$ \\
\hline OX-24 & 7.5:15:71.1:110:24-NaCl & 1.55 & 10.5 & 65 & 0.33 \\
\hline OX-25 & 7.5:15:71.1:110:28-NaCl & 1.55 & 12.1 & 62 & 0.26 \\
\hline
\end{tabular}

$R$ resorcinol, $F$ furfural, $M$ methanol, $W$ water, $I S$ inorganic salt, $O X$ organic xerogel

a Flocky resin

b Enhanced mechanical integrity and metallic gloss

c Organic-inorganic composite (inorganic salt was not removed from gel network)

\subsection{Characterization}

The obtained organic and related carbon xerogels are referred to in the paper as OX- $x$ and CX- $x$, respectively, where the $x$ refers to sample number. The bulk densities of organic xerogels were calculated from the mass and dimensions of the samples. Selected organic and carbon xerogels were investigated by means of SEM, XRD and $\mathrm{N}_{2}$ physisorption techniques. A scanning electron microscope (SEM), operating at an accelerating voltage of $2 \mathrm{kV}$ (LEO 1530 apparatus), was used to study the microstructure of the samples of organic and carbon xerogels. To study the structural appearance of CXs, X-ray diffraction (XRD) was performed (using a Siemens D500 powder difractometer with $\mathrm{CuK} \alpha$ radiation) with a scan range of $2 \theta$ from $10^{\circ}$ to $60^{\circ}$. The average values of the crystallite size were obtained using Scherrer's equation. The textural properties of carbon xerogels were measured by $\mathrm{N}_{2}$ adsorption at $-196^{\circ} \mathrm{C}$ on ASAP 2010 surface area analyzer (Micromeritics). Before adsorption measurements, each sample of approximately $0.1 \mathrm{~g}$ was outgassed under vacuum for $2 \mathrm{~h}$ at $250{ }^{\circ} \mathrm{C}$. The Brunauer-Emmett-Teller specific surface area $\left(\mathrm{S}_{\mathrm{BET}}\right)$ was calculated from the nitrogen adsorption isotherm with a range of relative pressures from 0.05 to 0.25 . The volume of micropores $\left(\mathrm{V}_{\text {mic }}\right)$ was determined by the $\alpha_{\mathrm{s}}$-plot method using carbon black Cabot BP280 as the reference [59]. The total pore volume $\left(\mathrm{V}_{t}\right)$ was estimated from the volume adsorbed at a relative pressure of $\sim 0.99$. The volume of mesopores $\left(\mathrm{V}_{\text {mes }}\right)$ was calculated from total pore volume and the volume of micropores. 
Table 2 Organic xerogel recipes and impact of the precursor sol composition with addition of $\mathrm{NH}_{4} \mathrm{ClO}_{4}$ on the drying shrinkage and density of organic xerogel

\begin{tabular}{|c|c|c|c|c|c|}
\hline Test no. & $\begin{array}{l}\text { Examined materials } \\
\text { (starting solution consisting } \\
\text { of R:F:M:W:IS-formula, amount } \\
\text { of substances [g]) }\end{array}$ & $\begin{array}{l}\mathrm{H}_{2} \mathrm{O} / \mathrm{MeOH} \text { mass } \\
\text { ratio }\end{array}$ & $\begin{array}{l}\text { Salt } \\
\text { content (wt } \%)\end{array}$ & $\begin{array}{l}\text { Drying shrink } \\
(\%) \pm 5\end{array}$ & $\begin{array}{l}\text { Density }\left(\mathrm{g} / \mathrm{cm}^{3}\right) \\
\pm 0.05\end{array}$ \\
\hline OX-26 & $15: 30-39.5-100: 19-\mathrm{NH}_{4} \mathrm{ClO}_{4}$ & 2.53 & 9.3 & 23 & 0.29 \\
\hline OX-27 & $15: 30-47.5-100: 19-\mathrm{NH}_{4} \mathrm{ClO}_{4}$ & 2.11 & 8.9 & 26 & 0.30 \\
\hline OX-28 & $15: 30-55.3-100: 19-\mathrm{NH}_{4} \mathrm{ClO}_{4}$ & 1.81 & 8.6 & 35 & 0.33 \\
\hline OX-29 & 15:30:31.6:100:14- $\mathrm{NH}_{4} \mathrm{ClO}_{4}$ & 3.16 & 7.3 & 24 & 0.31 \\
\hline OX-30 & 15:30:31.6:100:19- $\mathrm{NH}_{4} \mathrm{ClO}_{4}$ & 3.16 & 9.7 & 17 & 0.27 \\
\hline OX-31 & 15:30:31.6:100:19- $\mathrm{NH}_{4} \mathrm{ClO}_{4}-\mathrm{HCl}$ free & 3.16 & 9.7 & - & Precipitate $^{a}$ \\
\hline OX-32 & 15:30:31.6:100:24- $\mathrm{NH}_{4} \mathrm{ClO}_{4}$ & 3.16 & 11.9 & 21 & 0.27 \\
\hline OX-33 & $15: 30: 31.6: 100: 30-\mathrm{NH}_{4} \mathrm{ClO}_{4}$ & 3.16 & 14.5 & 18 & 0.28 \\
\hline
\end{tabular}

$R$ resorcinol, $F$ furfural, $M$ methanol, $W$ water, $I S$ inorganic salt, $O X$ organic xerogel

a Flocky resin

Table 3 Organic xerogel recipes and impact of the precursor sol composition with addition of $\mathrm{FeCl}_{3}$ on the drying shrinkage and density of organic xerogel

\begin{tabular}{|c|c|c|c|c|c|}
\hline Test no. & $\begin{array}{l}\text { Examined materials } \\
\text { (starting solution consisting } \\
\text { of R:F:M:W:IS-formula, } \\
\text { amount of substances }[\mathrm{g}] \text { ) }\end{array}$ & $\begin{array}{l}\mathrm{H}_{2} \mathrm{O} / \mathrm{MeOH} \\
\text { mass ratio }\end{array}$ & $\begin{array}{l}\text { Salt concentration } \\
(\mathrm{wt} \%)\end{array}$ & $\begin{array}{l}\text { Drying shrink } \\
(\%) \pm 5\end{array}$ & Density $\left(\mathrm{g} / \mathrm{cm}^{3}\right) \pm 0.05$ \\
\hline OX-34 & $7.5: 15: 71.1: 70: 25-\mathrm{FeCl}_{3}$ & 0.98 & 13.3 & 61 & Cracking $^{\mathrm{a}, \mathrm{b}}$ \\
\hline $\mathrm{OX}-34 / \mathrm{FeCl}_{3}^{\mathrm{c}}$ & 7.5:15:71.1:70:25- $\mathrm{FeCl}_{3}$ & 0.98 & 13.3 & 61 & 1.5 composite $\mathrm{R}-\mathrm{F} / \mathrm{FeCl}_{3}^{\mathrm{b}}$ \\
\hline OX-35 & 7.5:15:55.3:70:25- $\mathrm{FeCl}_{3}$ & 1.27 & 14.5 & 27 & 0.30 \\
\hline OX-36 & 7.5:15:71.1:70:12- $\mathrm{FeCl}_{3}$ & 0.98 & 6.8 & 59 & Cracking $^{\mathrm{a}, \mathrm{b}}$ \\
\hline OX-37 & 7.5:15:31.6:70:12- $\mathrm{FeCl}_{3}$ & 2.22 & 8.8 & 21 & 0.27 \\
\hline OX-38 & $7.5: 15: 31.6: 70: 25-\mathrm{FeCl}_{3}$ & 2.22 & 16.8 & - & Precipitate $^{\mathrm{d}}$ \\
\hline
\end{tabular}

$R$ resorcinol, $F$ furfural, $M$ methanol, $W$ water, $I S$ inorganic salt, $O X$ organic xerogel

a Cracking (occuring during the drying and salt removing) leads to the sample breakage. This occurs for samples which displays small pores, i.e. synthesized at low $\mathrm{H}_{2} \mathrm{O} / \mathrm{MeOH}$ ratio

b Enhanced mechanical integrity

c Organic-inorganic composite (inorganic salt was not removed from gel network)

d Flocky resin

\section{Results}

\subsection{Physical and textural properties of OXs and CXs}

Depending on the composition of precursor mixtures (shown in the second column in Tables 1, 2, 3), the obtained xerogels differ significantly in appearance. Regardless of the salt chemical formula, a high $\mathrm{H}_{2} \mathrm{O}$ / $\mathrm{MeOH}$ ratio and/or high salt concentration leads to spongylike gels with low mechanical strength (very brittle materials easy to break by hand) and eventually a flocky precipitate is obtained instead of a monolithic gel (OX-5). Also when $\mathrm{HCl}$ was not added, the mixture precipitates as a flocky resin $(\mathrm{OX}-12,-31)$, so that the $\mathrm{HCl}$ catalyst was essential to obtain monoliths from mixtures with $\mathrm{NaCl}$ or $\mathrm{NH}_{4} \mathrm{ClO}_{4}$. A low $\mathrm{H}_{2} \mathrm{O} / \mathrm{MeOH}$ ratio (high methanol concentration) with no added salt led to uniform gels that shrink a lot during drying. As a result, a dense (up to $1.23 \mathrm{~g} / \mathrm{cm}^{3}$ ), rigid and non-porous R-F xerogel characterized by high mechanical strength and metallic gloss is obtained (OX-7).

When the $\mathrm{H}_{2} \mathrm{O} / \mathrm{MeOH}$ ratio increases (Table 1, OX-17, $-18,-19)$, porous materials can be obtained without any added salt and eventually the R-F polymer precipitates. In that case the miscibility of furfural in the water/methanol mixture is limited, so that the $\mathrm{H}_{2} \mathrm{O} / \mathrm{MeOH}$ ratio is the only factor impacting gel structure. This procedure can be applied to prepare R-F xerogels with high purity. However, 
Table $4 \mathrm{~S}_{\mathrm{BET}}$ values for investigated CXs in different carbonization conditions

\begin{tabular}{|c|c|c|}
\hline Test no. & $\begin{array}{l}\mathrm{S}_{\mathrm{BET}}\left(\mathrm{m}^{2} / \mathrm{g}\right) \text { of } \mathrm{CXs} \\
10^{\circ} \mathrm{C} / \mathrm{min} 2 \mathrm{~h} \\
1,000^{\circ} \mathrm{C}, \pm 10\end{array}$ & $\begin{array}{l}\mathrm{S}_{\mathrm{BET}}\left(\mathrm{m}^{2} / \mathrm{g}\right) \text { of } \mathrm{CXs} \\
3{ }^{\circ} \mathrm{C} / \mathrm{min} 2 \mathrm{~h} \\
900{ }^{\circ} \mathrm{C}, \pm 10\end{array}$ \\
\hline CX-1 & 363 & - \\
\hline CX-2 & 385 & 520 \\
\hline CX-3 & 492 & - \\
\hline CX-6 & 259 & - \\
\hline CX-7 & Non-porous & - \\
\hline CX-8 & 397 & 538 \\
\hline CX-9 & 377 & - \\
\hline CX-10 & 378 & 497 \\
\hline CX-11 & 386 & - \\
\hline CX-13 & 387 & 557 \\
\hline CX-22 & 396 & - \\
\hline CX-23 & - & 581 \\
\hline CX-24 & 398 & - \\
\hline CX-29 & 497 & 528 \\
\hline CX-32 & $\begin{array}{l}478 \text { (and } 424 \text { after } \\
\text { carbonization at } 600{ }^{\circ} \mathrm{C} \text { ) }\end{array}$ & 555 \\
\hline CX-34 & - & 463 \\
\hline CX-35 & - & 317 \\
\hline
\end{tabular}

we did not explore this research direction. Instead, we focused on mixtures with added salt because these can be useful for potentially easy gel doping and simultaneous structure control. In fact, for $\mathrm{a}_{2} \mathrm{O} / \mathrm{MeOH}$ ratio as high as 3.16 , a monolithic gel with very high salt content can still be obtained (OX-32, -33) and the gel structure can be controlled by methanol content. Comparing a series of samples from OX-7 to OX-14, where only the amount of salt was changed in the starting solution, we observed that by increasing salt concentration the uniformity and density of the final xerogel clearly decreases. The impact of the amount of salt added on the uniformity of the produced gel becomes stronger as the $\mathrm{H}_{2} \mathrm{O} / \mathrm{MeOH}$ mass ratio increases. If the ratio of $\mathrm{H}_{2} \mathrm{O} / \mathrm{MeOH}$ is below 1.45 (samples OX-20/ $\mathrm{NaCl}, \mathrm{OX}-34 / \mathrm{FeCl}_{3}, \mathrm{OX}-36$ ), a large amount of $\mathrm{NaCl}$ or $\mathrm{FeCl}_{3}$ can be added to the precursor mixture, and as a result an R-F xerogel/metal chloride (organic/inorganic) composite is obtained with high uniformity, high density and mechanical strength (rigid materials breakable by hammer).

During drying all produced organic gels shrink. Significant gel shrinkage results in high density and enhanced mechanical integrity of the obtained xerogels (OX-7, -8, $-23,-34,-36)$. The density and shrinkage of xerogels can be easily controlled by the $\mathrm{H}_{2} \mathrm{O} / \mathrm{MeOH}$ ratio and the salt content in the starting solution. We observed that by halving the resorcinol and furfural concentration in the starting solution the density of the final xerogels cannot be significantly reduced owing to the increasing shrinkage (reduced gel framework strength, OX-21 to -25).

The BET specific surface areas determined for two different carbonization conditions are listed in Table 4. As it was commonly observed in previous research [42], increasing the carbonization temperature and the carbonization rate significantly decreases the final $S_{\mathrm{BET}}$ surface area (microporosity decreases). Changing the salt and methanol content in the starting mixture of precursors does not regularly affect the $S_{\mathrm{BET}}$ surface area values of the final carbon xerogels.

Figures 1 and 2 depict the $\mathrm{N}_{2}$ adsorption-desorption isotherms of selected CXs. The isotherms rose very sharply at low relative pressures, which indicates the abundant microporosity of investigated materials. Interestingly, the microporosity of CXs derived from mixtures with $\mathrm{FeCl}_{3}$ is depleted in comparison with other samples. According to the IUPAC classification, the isotherms of CX-2, -10, -13, -30 and -33 exhibit type I isotherms, suggesting their

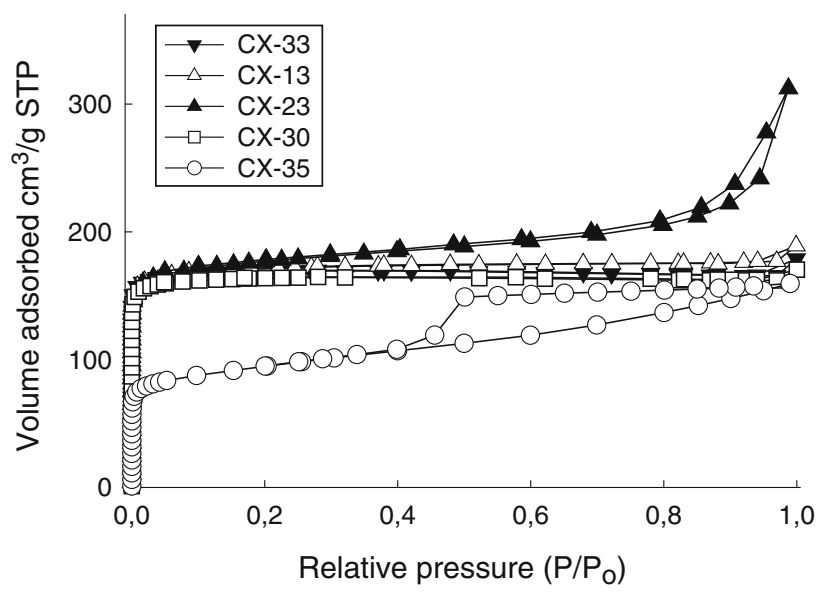

Fig. 1 Nitrogen adsorption and desorption isotherms of CXs-13, -23, $-30,-33,-35$ after carbonization at $900{ }^{\circ} \mathrm{C}$

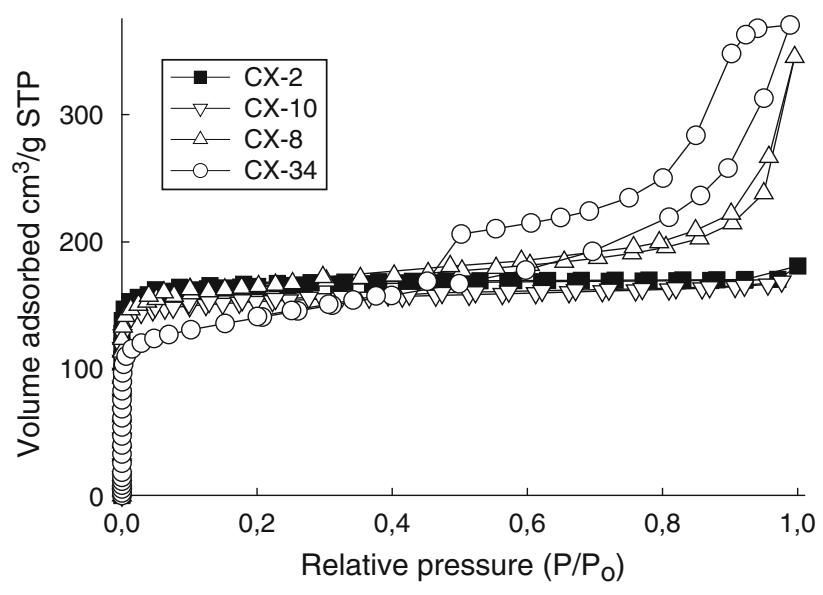

Fig. 2 Nitrogen adsorption and desorption isotherms of CXs-2, -8, $-10,-34$ after carbonization at $900{ }^{\circ} \mathrm{C}$ 
exclusively microporous structure [60]. CX-8 and -23 exhibit type IV isotherms with a hysteresis loop (H3) at high relative pressures, a feature that is typically associated with capillary condensation within mesopores. However, these samples do not reach an adsorption plateau at high relative pressures, which indicates that the mesopore system is irregular and expanding into a macropore regime $[29,41,60]$. CX-34 and -35 posses even more developed mesoporosity characterized by larger, irregular mesopores (type IV isotherms with wide hysteresis loop in the $\mathrm{p} / \mathrm{p}_{\mathrm{o}}$ range of $0.4-1$ ).

For some chosen samples carbonized at $900{ }^{\circ} \mathrm{C}$, additional textural properties are listed in Table 5. It is important to bear in mind that since the $\mathrm{N}_{2}$ adsorption is limited to pores smaller than $50 \mathrm{~nm}$, the total void volume (sum of micro-, meso-, and macropores volume) cannot be measured by this technique. For samples containing macropores and/or isotherms without plateau at saturation, the $\mathrm{V}_{\mathrm{t}}$ measured by nitrogen adsorption does not mean total void volume.

Even though mesopores constitute at least $50 \%$ of the entire porosity of CX-8 -23 (i.e. entire porosity that can be measured with $\mathrm{N}_{2}$ low temperature adsorption), and much more of CX-34 and -35, their size range is large, making it difficult to assess the average size of these mesopores. Sample CX-34 derived from a mixture with $\mathrm{FeCl}_{3}$ is predominantly mesoporous $\left(\mathrm{V}_{\text {mes }}=0.43 \mathrm{~cm}^{3} / \mathrm{g}\right)$ and is characterized by the highest $\mathrm{V}_{\mathrm{t}} \sim 0.6 \mathrm{~cm}^{3} / \mathrm{g}$.

\subsection{Morphology of OXs and CXs}

The morphology of xerogels was evaluated using scanning electron microscopy. As seen in the SEM micrographs (Figs. 3, 4, 5), the carbon xerogel morphology differs in particle size and shape depending on the condensation

Table 5 Some porous textural parameters of chosen samples carbonized at $900{ }^{\circ} \mathrm{C}$

\begin{tabular}{llll}
\hline Test no. & $\begin{array}{l}\mathrm{V}_{\text {mic }}\left(\mathrm{cm}^{3} / \mathrm{g}\right) \\
\pm 0.03\end{array}$ & $\begin{array}{l}\mathrm{V}_{\text {mes }}\left(\mathrm{cm}^{3} / \mathrm{g}\right) \\
\pm 0.03\end{array}$ & $\begin{array}{l}\mathrm{V}_{\mathrm{t}}\left(\mathrm{cm}^{3} / \mathrm{g}\right)^{\mathrm{a}} \\
\pm 0.03\end{array}$ \\
\hline CX-2 & 0.26 & - & 0.26 \\
CX-8 & 0.22 & 0.31 & 0.53 \\
CX-10 & 0.25 & 0.01 & 0.26 \\
CX-13 & 0.28 & 0.01 & 0.29 \\
CX-23 & 0.25 & 0.24 & 0.49 \\
CX-30 & 0.25 & - & 0.25 \\
CX-33 & 0.26 & 0.01 & 0.27 \\
CX-34 & 0.16 & 0.43 & 0.59 \\
CX-35 & 0.10 & 0.15 & 0.25 \\
\hline
\end{tabular}

a All presented materials possess macropores (pores above $>50 \mathrm{~nm}$ ) thus $\mathrm{V}_{\mathrm{t}}$ does not correspond to the total voids volume (macroporosity not counted) conditions (please note the different magnification of the images). Their size ranges widely, from c.a. $5 \mu \mathrm{m}$ (Fig. 3, CX-3, Fig. 4, CX-30, Fig. 5, CX-37) to c.a. $50 \mathrm{~nm}$ (Fig. 3, CX-23, Fig. 5, CX-34, -36). The bigger the particles are the more regular shapes they have. In the micrometer scale they occur as perfect spheres (Fig. 4, CX-32). The morphology of the material remains unchanged when an organic xerogel is transferred into a carbon xerogel (Fig. 4, OX-30, CX-30). Open-celled, macroporous, colloidal structures were obtained for high $\mathrm{H}_{2} \mathrm{O} / \mathrm{MeOH}$ ratios and/or high salt contents in the starting mixtures (e.g. CX-3, -13, $-30,-32,-33,-37)$. Comparing the morphology of CX-26 and CX-30 (Fig. 4), one can say that if the salt amount is kept constant, increases in the $\mathrm{H}_{2} \mathrm{O} / \mathrm{MeOH}$ ratio result in larger $\mathrm{CX}$ particles. If the $\mathrm{H}_{2} \mathrm{O} / \mathrm{MeOH}$ ratio is kept constant, increases in the amount of salt result in larger $\mathrm{CX}$ particles (CX-8, -9, -10, -13, Fig. 3). CX-8 looks like a continuous polymer, whereas $\mathrm{CX}-13$ represents an assembly of individual spherical particles. The magnified SEM image reveals that the surface of the spherical particles of colloidal CXs (CX-32, Fig. 4) is clean and smooth. If the salt is not entirely removed it can be observed on the carbon spheres. The surface of sample CX-3A (Fig. 3) has many lumps adhering to the surface. The lumps are $\mathrm{NaCl}$ residue that crystallized on the particle surface and went through carbonization. They can be completely removed through post-carbonization water washing (CX-3B, Fig. 3).

Mesoporous, nanosized structures were obtained from starting mixtures with low $\mathrm{H}_{2} \mathrm{O} / \mathrm{MeOH}$ ratios or low salt content. These conditions enhance smaller (nanometric) and better connected gel particles constituting a polymericlike structure. In CX-8, -23, -34 and -36 (Figs. 3 and 5) the particles seem to be coarse and coalesce together via thick necks, while particles in samples CX-33 and -37 are well separated microspheres.

The SEM study also reveals interesting information about the porous structure of the investigated samples. The $\mathrm{N}_{2}$ adsorption technique is useful only in the analysis of pores smaller than $50 \mathrm{~nm}$ in diameter, so that the large voids between the colloidal CX spheres (inter-granular porosity) were not evaluated [18]. It can be concluded that the high surface area of samples with microcellular, colloidal structure (CX-33, -30,-2, -13 and -10) is due to microporosity within the carbon framework spheres. The microporous $\mathrm{CX}$ spheres coalesce through a pearly structure (3D network) to form a large macropore space with well-developed pore interconnectivity. Due to this bimodal porous structure, such samples can be dried at ambient conditions without significant volume shrinkage. Unfortunately, the presence of large pores makes the xerogels fragile. The nano-network of CX-8, -23, -34 and -36 collapsed to some extent during the ambient pressure drying process because of the large capillary pressure caused by 

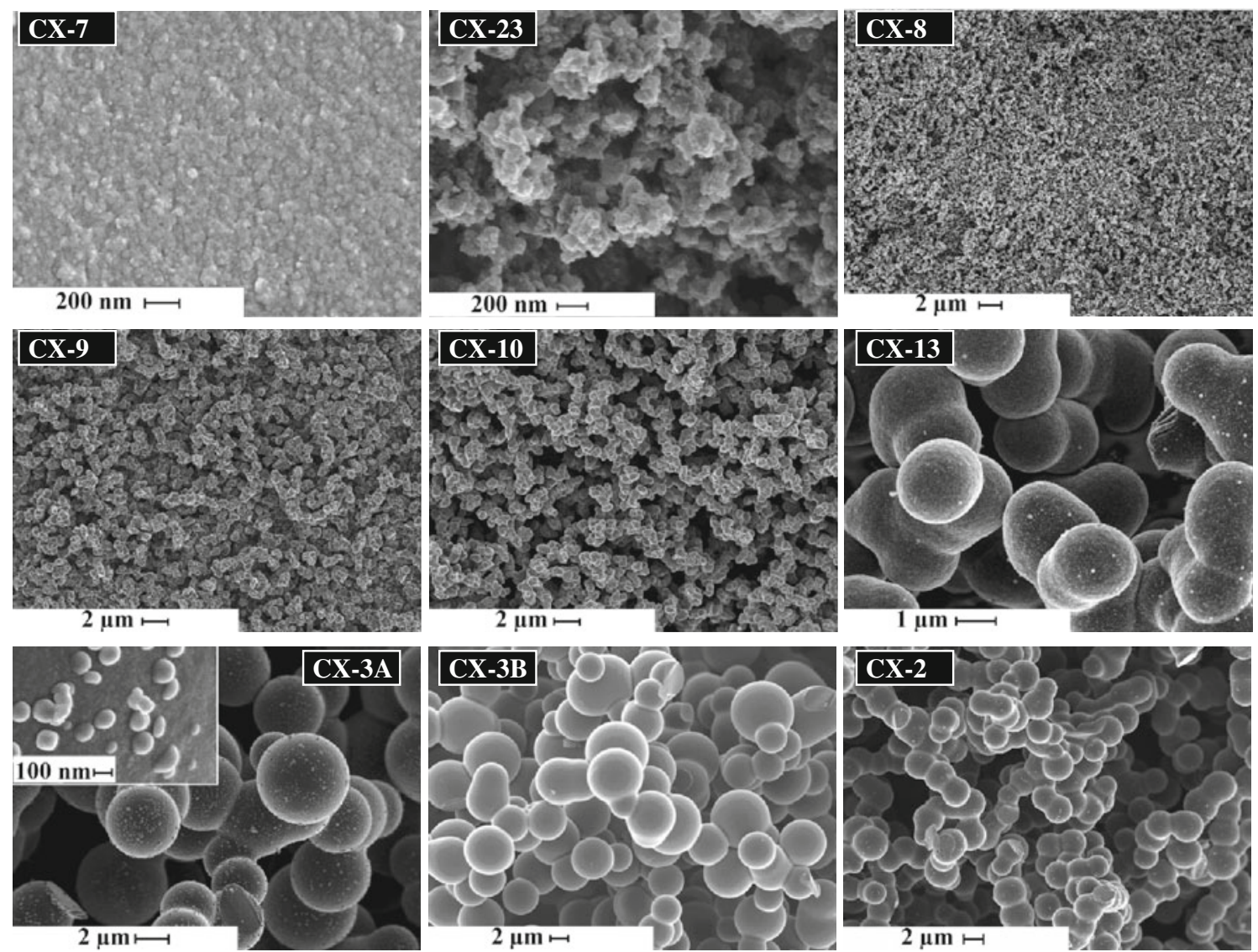

Fig. 3 SEM images of carbon xerogels derived from mixtures with $\mathrm{NaCl}$. CX-3A—sample before, and CX-3B-sample after additional water purification
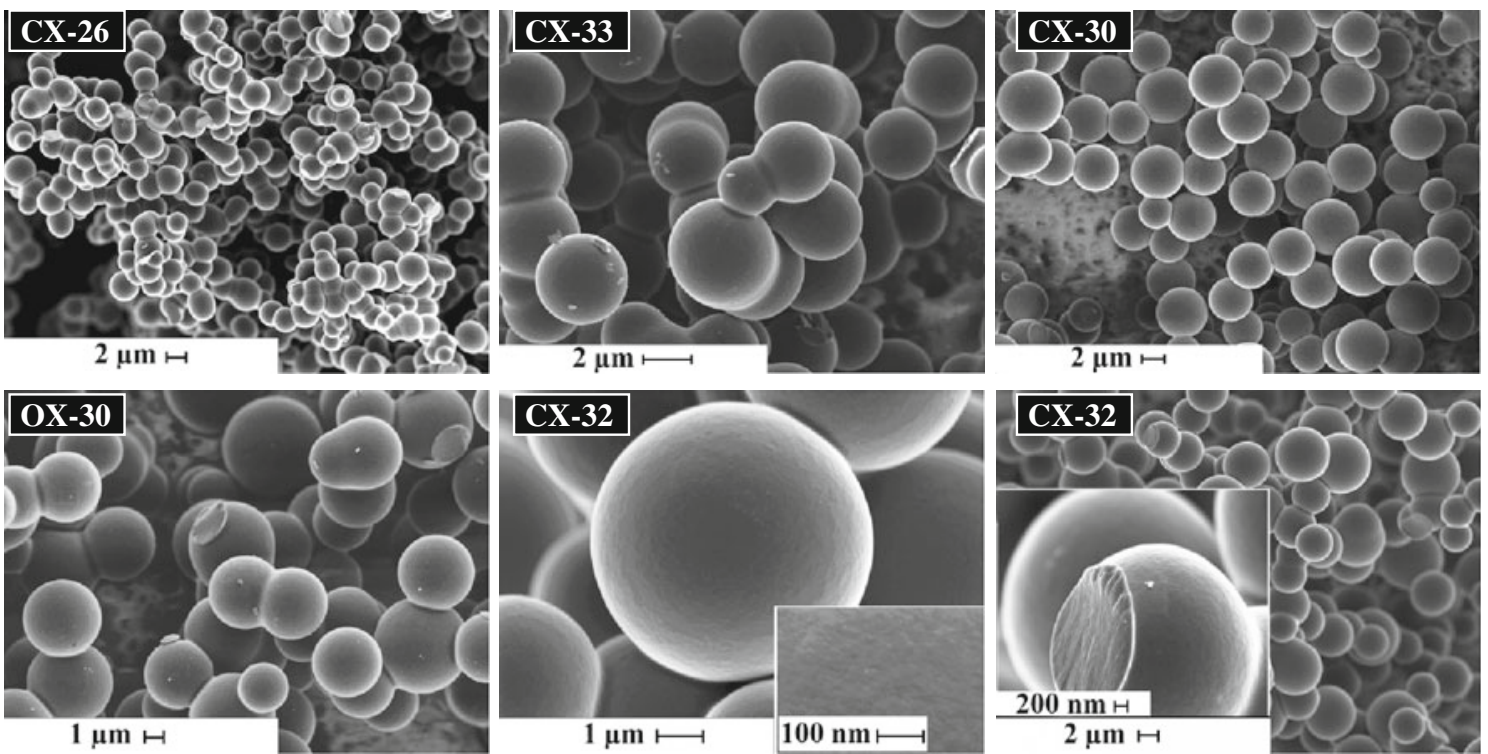

Fig. 4 SEM images of organic and carbon xerogels derived from mixtures with $\mathrm{NH}_{4} \mathrm{ClO}_{4}$. Magnified pictures of CX-32 show exclusively microporous structure inside the carbon spheres 

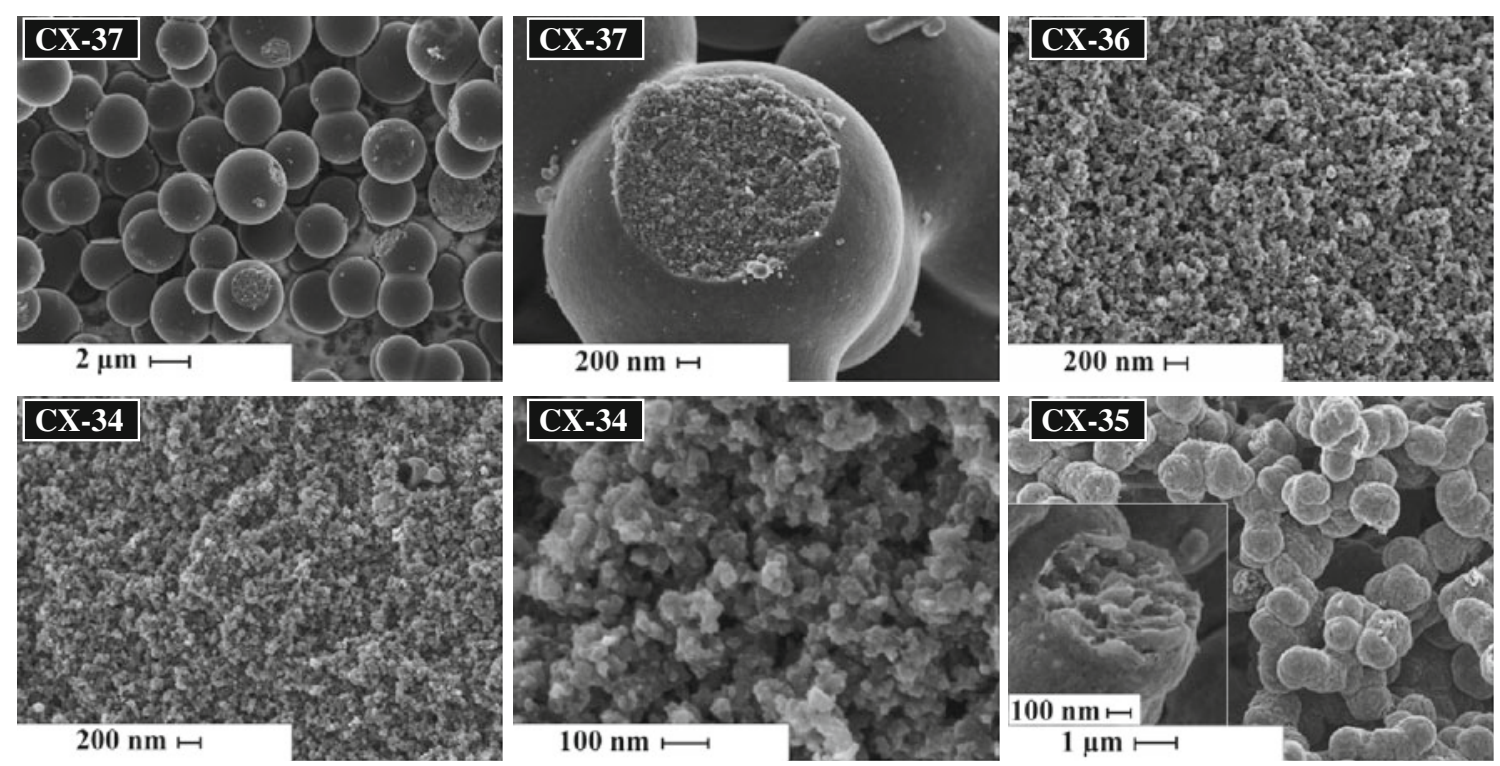

Fig. 5 SEM images of carbon xerogels derived from mixtures with $\mathrm{FeCl}_{3}$. Magnified pictures of $\mathrm{CX}-37$ and -35 show their developed mesoporosity inside the carbon colloidal particles

the lack of micron-sized porosity. As a result, these samples possess high bulk density. Sample CX-7 with volumetric shrinkage of $85 \%$ is totally non-porous (Fig. 3).

\subsection{Structural investigation by X-ray analysis}

The X-ray diffraction patterns for the carbon xerogels derived from carbonization of water-purified organic xerogels at $900{ }^{\circ} \mathrm{C}$ are shown in Figs. 6 and 7. All these CXs derived from mixtures with $\mathrm{NaCl}$ or $\mathrm{NH}_{4} \mathrm{ClO}_{4}$ possess very broad peaks centered at $2 \theta \sim 20^{\circ}$ and at $2 \theta \sim 43^{\circ}$. The signal around $20^{\circ}$ is associated with the ordering of graphene sheets in the (002) direction and in the CX-23, -13 and -30 samples it is shifted to lower angles. The peak

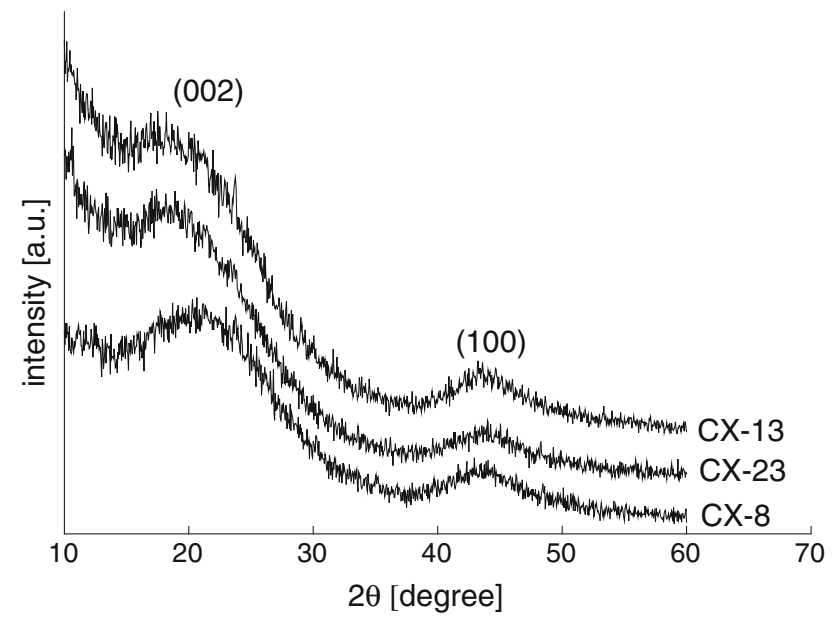

Fig. 6 XRD profiles of carbon xerogels CX-8, -13, -23 pyrolyzed at $900{ }^{\circ} \mathrm{C}$

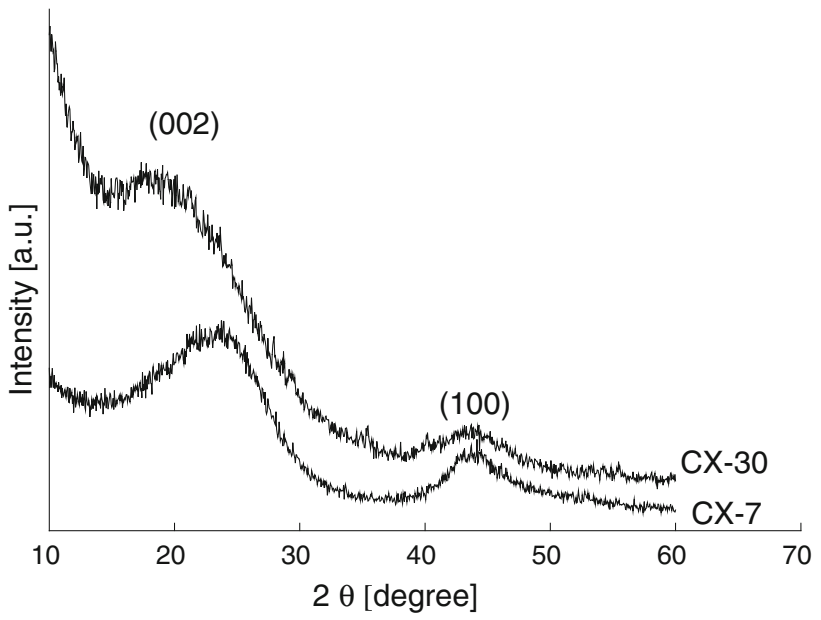

Fig. 7 XRD profiles of carbon xerogels CX-30 and CX-7 pyrolyzed at $900{ }^{\circ} \mathrm{C}$

around $43^{\circ}$ may correspond to the (100) diffraction peak of graphite. The broad bands and shifting tendency indicate the amorphous structure of all examined materials. Figure 7 compares macro-microporous CX-30 with non-porous CX-7. One can say that the non-porous xerogel has significantly better ordered microstructure-the (002) peak is more intensive and shifted to higher angles in comparison to the other samples. Nonetheless, analysis of both the position and shape of the Bragg's peaks suggests very disordered, turbostratic structures [61] of all these carbon xerogels.

Carbon xerogels obtained from carbonization of organic xerogel OX-37 (derived from mixtures with $\mathrm{FeCl}_{3}$ ) possess completely different crystalline structure (Fig. 8). Intense 


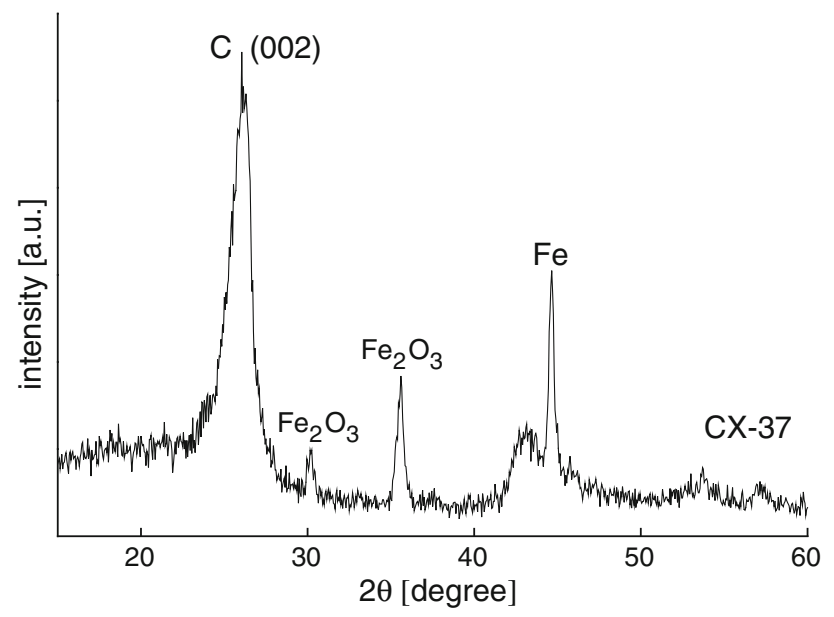

Fig. 8 XRD profile of carbon xerogel CX-37 pyrolyzed at $1,000{ }^{\circ} \mathrm{C}$

diffraction peaks, associated with crystalline iron and carbon, appear after pyrolysis. That suggests that in spite of water purification some iron remains bonded to the organic xerogel matrix. Since no crystalline iron form can be detected in water-purified OX-37 (Fig. 9), and prior to carbonization this material is completely amorphous, it can be concluded that iron is bonded to the organic matrix in ionic state. During the pyrolysis iron ions are reduced to metallic iron with the average particle size of about $30 \mathrm{~nm}$. The created Fe catalyzes low temperature graphitization of amorphous carbon which results in graphitic carbon/iron composites [8, 62]. The presence of $\mathrm{Fe}_{2} \mathrm{O}_{3}$ can be explained by air oxidation of nanometric Fe particles.

As shown in Fig. 10, carbonization of an organic xero$\mathrm{gel} / \mathrm{FeCl}_{3}$ composite (the sample was not water-purified) leads to a graphitic carbon/Fe composite with abundant $\mathrm{Fe}_{3} \mathrm{C}$ phase. The obtained $\mathrm{CX}$ possesses a high level of crystallization $\left(\mathrm{L}_{\mathrm{c}}=10 \mathrm{~nm}, \mathrm{~d}_{002}=0.338 \mathrm{~nm}\right)$. The sharp and very narrow diffraction peak associated with the $\mathrm{Fe}$ phase suggests the presence of well crystallized iron grains

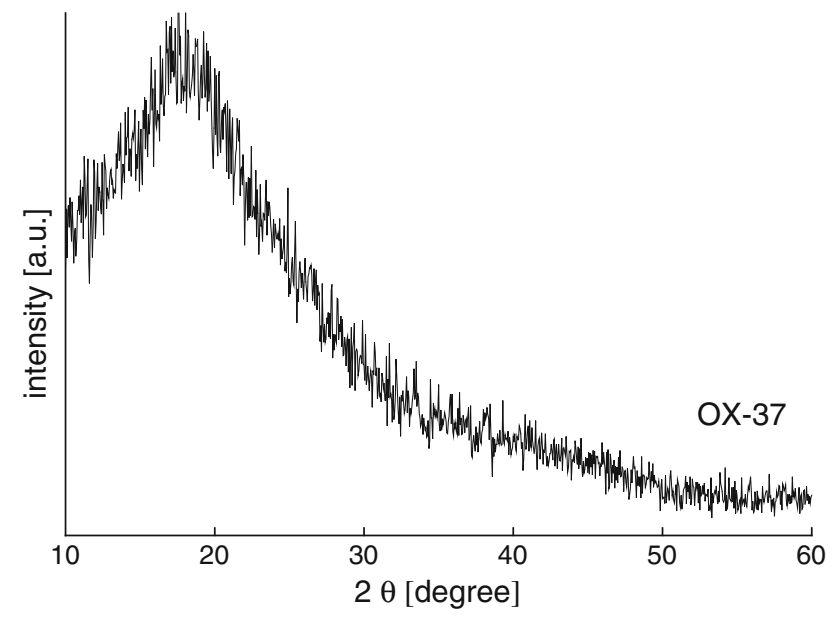

Fig. 9 XRD profile of organic xerogel OX-37

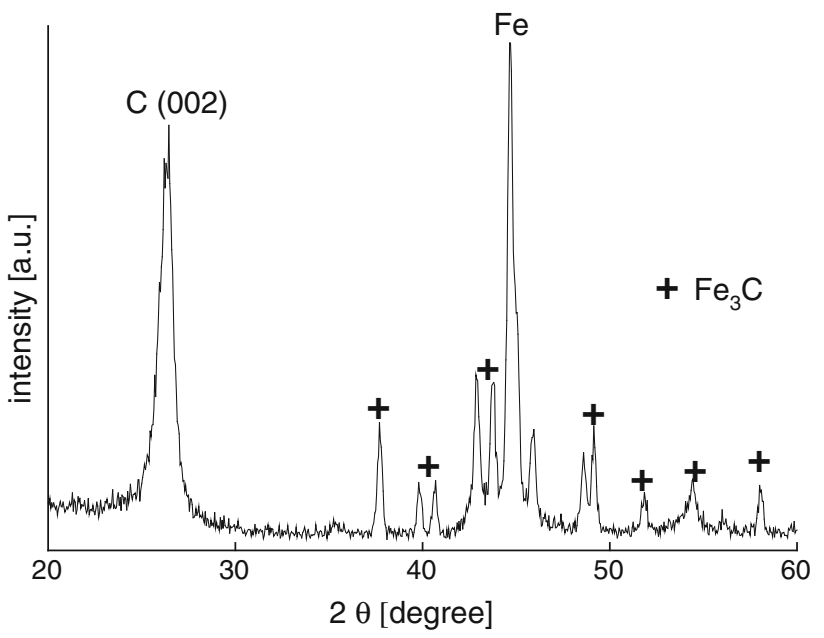

Fig. 10 XRD profile of carbon xerogel-iron composite: CX-34/Fe derived from pyrolysis of the $\mathrm{OX}-34 / \mathrm{FeCl}_{3}$ composite at $900{ }^{\circ} \mathrm{C}$

with average size of $26 \mathrm{~nm}$, assessed using Scherrer's equation. Fe can be easily removed from the carbon xerogel structure by immersing in $\mathrm{HCl}$, which shows that $\mathrm{Fe}$ is accessible and not isolated from the environment by carbon layers. Calculated from the weight of the sample before and after $\mathrm{HCl}$ purification, $\mathrm{Fe}$ (more precisely $\mathrm{Fe}$, $\mathrm{Fe}_{3} \mathrm{C}$ ) constitutes about $30 \%$ of the $\mathrm{CX} / \mathrm{Fe}$ composite obtained from the $\mathrm{OX}-34 / \mathrm{FeCl}_{3}$ composite.

\section{Discussion}

As observed, the gel network can be easily manipulated in the micro- and nanoscale by controlling the water/methanol ratio and inorganic salt concentration in the precursor's mixture. Increasing the $\mathrm{H}_{2} \mathrm{O} / \mathrm{MeOH}$ ratio leads to a loss of mechanical strength in the CXs (the samples predominantly contain large macropores), while gradually decreasing the $\mathrm{H}_{2} \mathrm{O} / \mathrm{MeOH}$ ratio results in smaller pores, and eventually leads to rigid non-porous solids. For a given $\mathrm{H}_{2} \mathrm{O} / \mathrm{MeOH}$ ratio, a change in salt concentration causes similar effects.

The carbon xerogels possess two types of pores: voids between the carbonized particles (meso- and macropores) and voids inside the xerogel particles (micro-, and mesopores). From $\mathrm{N}_{2}$ sorption analysis one can conclude that CXs obtained from solutions with high methanol content contain pores with a wide range of sizes that cross the micropore-mesopore boundary [60]. Such materials yield isotherms with no distinctive plateau. The presence of mesopores can be detected by the appearance of a hysteresis loop as in Figs. 1, 2 (CX-8, -23 and -34). An upward deviation which occurs at high $\mathrm{p} / \mathrm{p}_{\mathrm{o}}$ indicates that this mesoporous system expands into macroporous one. All CXs obtained from mixtures with high $\mathrm{H}_{2} \mathrm{O} / \mathrm{MeOH}$ ratio 
(with colloidal structure) appear to be exclusively microporous (micropores inside the carbon spheres). An increase in the carbonization temperature and carbonization rate of $R-F$ xerogels significantly decreases the final $S_{B E T}$ surface area. The microporosity of carbon gels gradually disappears as the pyrolysis temperature increases [1, 42, 63-65]. Yet the variations in the $\mathrm{H}_{2} \mathrm{O} / \mathrm{MeOH}$ ratio and salt amount used to prepare xerogels affected only the meso- and macroporosity and not the micropore texture, which remains the same for samples obtained from mixtures with $\mathrm{NaCl}$ and $\mathrm{NH}_{4} \mathrm{ClO}_{4}$. That is not surprising since macroand mesoporosity is created during the sol-gel process as a result of phase separation, while microporosity is produced during the carbonization stage [66]. CX-35 and -34 posses much larger hysteresis loops comparing to other investigated samples. The presence of $\mathrm{FeCl}_{3}$ in the starting mixture results in samples with decreased microporosity and developed mesoporosity for both low and high $\mathrm{H}_{2} \mathrm{O} / \mathrm{MeOH}$ ratios. That is explained by iron presence in the waterpurified OXs samples. Resorcinol is a complexing agent towards $\mathrm{Fe}^{3+}$ ions [67]. Complexed iron ions cannot be effectively removed from gel framework by water washing. Additionally, as suggested in Ref. [4] iron ions in the xerogel can be chelated by two phenolic groups of the polymeric matrix. During carbonization complexed iron is reduced to the metallic state and causes partial carbon graphitization, which decreases the microporosity and develops the mesoporosity of CX-34, $-35[8,15,23,26]$.

As proposed, organic gel formation occurs through the polymerization-induced phase separation mechanism due to the growth of polymer chains and their decreasing solubility in the water phase $[45,68,69]$. The gel particle and pore sizes depend on the degree of crosslinking of the growing polymer chains before phase separation occurs. The longer the polymer remains in the solution, the smaller the final gel particles and pores are, since crosslinking between the chains is enhanced. The level of crosslinking on which phase separation occurs can be controlled by altering the $\mathrm{pH}$ of the precursor mixture. On the other hand, Job et al., [45, 46] reported that, for a given dilution and reagents ratio (resorcinol, formaldehyde), the initial $\mathrm{pH}$ is not the only factor affecting gel formation. The charge and concentration of the counter cations (of the 'catalyst', i.e. basification agent) also significantly modify gel texture. The impact of ions on the pore texture was explained by electrostatic effects on the microphase separation process that occurs before gelation. The effect of ions presented in the precursor mixture is not catalytic towards polymerization and gelation [45]. In the presence of ions, the polymerization-induced phase separation occurs earlier (at a lower degree of crosslinking), which leads to a microcellular structure. Following those observations we can conclude that inorganic salts (the ions of $\mathrm{NaCl}, \mathrm{NH}_{4} \mathrm{ClO}_{4}$,
$\mathrm{FeCl}_{3}$ ) accelerate phase separation by triggering demixion-they destabilize the R-F polymer suspension by screening the electrostatic repulsion between colloids. On the other hand, methanol delays phase separation by stabilizing the growing polymer chains in the liquid phase (solubility of the R-F oligomers is higher in methanol than in water). That allows better branching and crosslinking between the growing chains [69]. As a result, smaller gel particles and smaller pores are induced-polymeric structure. Finally, if the degree of crosslinking is too low, phase separation occurs on a macroscopic scale (for mixtures with high $\mathrm{H}_{2} \mathrm{O} / \mathrm{MeOH}$ ratio) and resin-like precipitate is obtained instead of a real gel (with nanosized pores) or even a colloidal gel. Detailed research and a summary concerning the synthesis conditions of carbon spheres and microcellular carbon are presented in Ref. [70]. The impact of co-solvents on the organic gel structure was also discussed in Ref. [71]. In that paper the authors pointed out that the nature of the solvent affects the polymerization kinetics. They supposed that the organic co-solvents affect the gelation process by increasing the interconnectivity or crosslinking of the polymer clusters that give rise to the primary particles, which is the same effect we observed herein.

Carbon xerogels derived from purified resorcinol-furfural gel represent a typical non-graphitized carbon and, after carbonization at $900{ }^{\circ} \mathrm{C}$, amorphous materials with some graphitic nano-domains cross-linked through $\mathrm{sp}^{3}$ coordinated carbons are obtained. As reported previously, if the integrity of the carbon bulk is disturbed by abundant porosity, only scattered graphite-like microcrystalline materials can be formed [72-74]. Drastic change of the structure of CXs is observed if the material is obtained from carbonization of the R-F precursor doped with $\mathrm{FeCl}_{3}$. During carbonization iron chloride is reduced to $\mathrm{Fe}$. Known as an excellent graphitization catalyst, $\mathrm{Fe}$ causes low-temperature carbon crystallization $[14,15,55,62]$, and as a result a CX with a significant amount of well crystallized carbon phase is produced. Interestingly, during carbonization the iron precursor was not only reduced, but also partially carburized, giving rise to a well crystallized iron carbide phase. As a result, the Fe-doped CX was found to contain a mixture of iron and iron carbide nanoparticles.

\section{Conclusion}

As we have shown, the co-solvent determines oligomer solubility (in our case increasing it) so that the water/cosolvent ratio allows control of the final gel morphology regardless of the inorganic salt concentration and type in the precursor mixture. The lower the $\mathrm{H}_{2} \mathrm{O} / \mathrm{MeOH}$ value, the longer the polymer remains in solvents (phase separation is 
delayed) thus the smaller the pore size-mesoporosity is enhanced, and macroporosity depleted. Consistently lowering the $\mathrm{H}_{2} \mathrm{O} / \mathrm{MeOH}$ ratio will finally result in rigid nonporous solids. In contrast, low methanol content yields colloidal macroporous samples that in turn lead to a loss of mechanical strength in the resulting CXs. Similarly, high salt concentration accelerates phase separation by launching demixion, leading to microcellular structures.

As we reported elsewhere, using other perchlorates or nitrates to dope resorcinol-aldehyde xerogels through a sol-gel process in a water-methanol mixture led to xerogel/salt composites with explosive properties, with salt loading as high as 50\% [52]. Their structure can be controlled by the $\mathrm{H}_{2} \mathrm{O} / \mathrm{MeOH}$ ratio. Considering the fact that three different salts (non-metallic $\mathrm{NH}_{4} \mathrm{ClO}_{4}$, alkali metal $\mathrm{NaCl}$, and transition metal $\mathrm{FeCl}_{3}$ ) were examined and taking into account the results presented in our previous research, it can be stated that solubilization of other inorganic salts in the water/methanol resorcinol-aldehyde solution should give similar results. Besides $\mathrm{FeCl}_{3}$, other transition metal chlorides like $\mathrm{NiCl}_{2}, \mathrm{CoCl}_{2}$ or $\mathrm{CuCl}_{2}$ may also be employed leading to carbon xerogel/metal composites with high metal loads and easily controlled structures. If polymerization is carried out in the solution with a large amount of good solvent for the polymer, it is possible to produce well crosslinked (nanosized) gels in the presence of very high concentrations of inorganic salts.

As in the example given herein, through this procedure R-F xerogels with $\mathrm{FeCl}_{3}$ doping above 50\% (OX-34/ $/ \mathrm{FeCl}_{3}$ ) can be obtained. After carbonization, Fe-doped carbon xerogels with iron loading of $30 \%$ are produced and the gel structure can be easily controlled by adjusting the $\mathrm{H}_{2} \mathrm{O}$ / $\mathrm{MeOH}$ ratio. Additionally, the polymeric matrix chemically bonds iron ions and it may lead to homogenous metal distribution, and thus to uniform graphitization.

This procedure may be applied to obtain highly saltdoped organic xerogels, highly metal-doped carbons, and if the metal is removed from the carbon xerogel structure, precious material for chemical energy storage devices, i.e. graphitic porous carbon, can be produced [15, 26, 30, 55]. In summary, the addition of methanol as a co-solvent can generate uniform highly doped organic and carbon xerogels, i.e. the phase separation which is quickened by the presence of ions can be efficiently delayed by methanol, thus enhancing crosslinking.

Acknowledgments The authors wish to acknowledge support from Prof. Stanisław Cudziło.

Open Access This article is distributed under the terms of the Creative Commons Attribution Noncommercial License which permits any noncommercial use, distribution, and reproduction in any medium, provided the original author(s) and source are credited.

\section{References}

1. Al-Muhtaseb SA, Ritter JA (2003) Adv Mater 15(2):101

2. Lorjai P, Chaisuwan T, Wongkasemjit S (2009) J Sol-Gel Sci Technol 52:56

3. Lu J, Wang X, Wang Y, Huang Q, Dai C, Gamboa S, Sebastian PJ (2008) J Non-Cryst Solids 354:19

4. Moreno-Castilla C, Maldonado-Hódar FJ, Pérez-Cadenas AF (2003) Langmuir 19:5650

5. Yoshizawa N, Hatori H, Soneda Y, Hanzawa Y, Kaneko K, Dresselhaus MS (2003) J Non-Cryst Solids 330:99

6. Bekyarova E, Kaneko K (2000) Adv Mater 12(21):1625

7. Wang H, Shu Y, Wang A, Wang J, Zheng M, Wang X, Zhang T (2008) Carbon 46:2076

8. Maldonado-Hódar FJ, Moreno-Castilla C, Rivera-Utrilla J, Hanzawa Y, Yamada Y (2000) Langmuir 16(9):4367

9. Bryning MB, Milkie DE, Islam MF, Hough LA, Kikkawa JM, Yodh AG (2007) Adv Mater 19:661

10. Bordjiba T, Mohamedi M, Dao LH (2008) Adv Mater 20:815

11. Maldonado-Hódar FJ, Pérez-Cadenas AF, Moreno-Castilla C (2003) Carbon 41:1291

12. Fu R, Dresselhaus MS, Dresselhaus G, Zheng B, Liu J, Satcher J Jr, Baumann TF (2003) J Non-Cryst Solids 318:223

13. Lv G, Wu D, Fu R, Zhang Z, Su Z (2008) J Non-Cryst Solids 354:4567

14. Steiner SA, Baumann TF, Kong J, Satcher JH Jr, Dresselhaus MS (2007) Langmuir 23:5161

15. Lu AH, Li WC, Salabas EL, Spliethoff B, Schüth F (2006) Chem Mater 18:2086

16. Mahata N, Pereira MFR, Suárez-García F, Martínez-Alonso A, Tascón JMD, Figueiredo JL (2008) J Colloid Interface Sci 324:150

17. Moreno-Castilla C, Maldonado-Hódar FJ, Rivera-Utrilla J, Rodríguez-Castellón E (1999) Appl Catal A 183:345

18. Job N, Marie J, Lambert S, Berthon-Fabry S, Achard P (2008) Energy Convers Manag 49:2461

19. Kadirvelu K, Goel J, Rajagopal C (2008) J Hazard Mater 153:502

20. Li J, Wang X, Huang Q, Gamboa S, Sebastian PJ (2006) J Power Sources 158:784

21. Wang J, Yang X, Wu D, Fu R, Dresselhaus MS, Dresselhaus G (2008) J Power Sources 185:589

22. Feaver A, Cao G (2006) Carbon 44:587

23. Carrott PJM, Marques LM, Ribeiro Carrott MML (2010) Micropor Mesopor Mater 131:75

24. Li GR, Feng ZP, Ou YN, Wu D, Fu R, Tong YX (2010) Langmuir 26(4):2209

25. Jae Lee Y, Chul Jung J, Park S, Gil Seo J, Baeck SH, Rag Yoon J, Yi J, Kyu Song I (2010) Curr Appl Phys 10:947

26. Wei S, Wu D, Shang X, Fu R (2009) Energy Fuels 23:908

27. Jin H, Zhanga H, Ma Y, Xu T, Zhong H, Wang M (2010) J Power Sources 195:6323

28. Yang W, Wu D, Fu R (2009) J Porous Mater 16:507

29. Li WC, Lu AH, Schüth F (2005) Chem Mater 17:3620

30. Hyeon T, Han S, Sung YE, Park KW, Kim YW (2003) Angew Chem Int Ed 42:4352

31. Moreno-Castilla C, Maldonado-Hódar FJ (2005) Carbon 43:455

32. Job N, Théry A, Pirard R, Marien J, Kocon L, Rouzauld JN, Béguin F, Pirard JP (2005) Carbon 43:2481

33. Wu D, Fu R (2008) J Porous Mater 15:29

34. Zhou J, Ji Y, He J, Zhang C, Zhao G (2008) Micropor Mesopor Mater 114:424

35. Brandt R, Petričević R, Pröbstle H, Fricke J (2003) J Porous Mater 10:171

36. Zhu Y, Hu H, Li W, Zhao H (2006) J Non-Cryst Solids 352:3358

37. Zhu Y, Hu H, Li WC, Zhang X (2006) J Power Sources 162:738 
38. Wu D, Fu R, Dresselhaus MS, Dresselhaus G (2006) Carbon 44:675

39. Wu D, Fu R, Zhang S, Dresselhaus MS, Dresselhaus G (2004) Carbon 42:2033

40. Job N, Sabatier F, Pirard JP, Crine M, Léonard A (2006) Carbon 44:2534

41. Léonard A, Job N, Blacher S, Pirard JP, Crine M, Jomaa W (2005) Carbon 43:1808

42. Job N, Pirard R, Marien J, Pirard JP (2004) Carbon 42:619

43. Job N, Panariello F, Marien J, Crine M, Pirard JP, Leonard A (2006) J Non-Cryst Solids 352:24

44. Zubizarreta L, Arenillas A, Menéndez JA, Pis JJ, Pirard JP, Job N (2008) J Non-Cryst Solids 354:4024

45. Job N, Gommes CJ, Pirard R, Pirard JP (2008) J Non-Cryst Solids $354: 4698$

46. Job N, Pirard R, Marien J, Pirard JP (2004) Carbon 42:3217

47. Maldonado-Hódar FJ, Ferro-Garcia AM, Riviera-Utrilla J, Moreno-Castilla C (1999) Carbon 37:1199

48. Maldonado-Hódar FJ, Moreno-Castilla C, Pérez-Cadenas AF (2004) Micropor Mesopor Mater 69:119

49. Fairén-Jiménez D, Carrasco-Marín F, Moreno-Castilla C (2006) Carbon 44:2301

50. Teipel U (2005) Energetic materials-particle processing and characterization. Wiley-VCH, Weinheim

51. Tappan BC, Brill TB (2003) Propellants Explos Pyrotech 28(2):72

52. Cudziło S, Kiciński W (2009) Propellants Explos Pyrotech 34:155

53. Job N, Pirard R, Vertruyen B, Colomer JF, Marien J, Pirard JP (2007) J Non-Cryst Solids 353:2333

54. Celorrio V, Calvillo L, Martínez-Huerta MV, Moliner R, Lázaro MJ (2010) Energy Fuels 24:3361

55. Han S, Yun Y, Park KW, Sung YE, Hyeon T (2003) Adv Mater 15(22): 1922
56. Figueiredo JL, Pereira MFR, Serp P, Kalck P, Samant PV, Fernandes JB (2006) Carbon 44:2516

57. Lambert S, Job N, D'Souza L, Pereira MFR, Pirarda R, Heinrichs B, Figueiredo JL, Pirarda JP, Regalbuto JR (2009) J Catal 261:23

58. Fu R, Zheng B, Liu J, Dresselhaus MS, Dresselhaus G, Satcher JH Jr, Baumann TF (2003) Adv Funct Mater 13(7):558

59. Kruk M, Jaroniec M, Gadkaree KP (1997) J Colloid Interface Sci 250:250

60. Rouquerol F, Rouquerol J, Sing K (1999) Adsorption by powders and porous solids. Principles, methodology and applications. Academic Press, San Diego

61. Biscoe J, Warren BE (1942) J Appl Phys 13:364

62. Oya A, Marsh H (1982) J Mater Sci 17:309

63. Lin C, Ritter JA (1997) Carbon 35:1271

64. Wu D, Fu R, Yu Z (2005) J Appl Polym Sci 96:1429

65. Pérez-Caballero F, Peikolainen AL, Uibu M, Kuusik R, Volobujeva O, Koel M (2008) Micropor Mesopor Mater 108:230

66. Burket CL, Rajagopalan R, Marencic AP, Dronvajjala K, Foley HC (2006) Carbon 44:2957

67. Liang C, Dai S, Guiochon G (2003) Anal Chem 75(18):4904

68. Pekala RW, Schaefer DW (1993) Macromolecules 26:5487

69. Serrano Aroca A, Monleón Pradas M, Gómez Ribellas JL (2007) Colloid Polym Sci 285:753

70. Scherdel C, Scherb T, Reichenauer G (2009) Carbon 47:2244

71. Fairèn-Jimènez D, Carrasco-Marín F, Moreno-Castilla C (2008) Langmuir 24:2820

72. Kuhn J, Brandt R, Mehling H, Petričević R, Fricke J (1998) J Non-Cryst Solids 225:58

73. Hanzawa Y, Hatori H, Yoshizawa N, Yamada Y (2002) Carbon 40:575

74. Guo T, Zhu J, Chen X, Song M, Zhang B (2007) J Non-Cryst Solids 353:2893 